\title{
ANÁLISE DA ADOÇÃO DAS IFRS PELAS COMPANHIAS ABERTAS BRASILEIRAS DO SETOR DE CONSTRUÇÃO
}

\author{
ANALYSIS OF ADOPTING IFRS FOR COMPANIES CONSTRUCTION SECTOR \\ BRAZILIAN
}

Rafaelle Gomes Firmino

rafaelle1011@hotmail.com

Universidade Estadual da Paraíba
Josélia Maria Rodrigues De Andrade

joseliarodrigues4@hotmail.com

Universidade Potiguar

RESUMO: Este estudo analisou a adoção as normas internacionais de contabilidade relativas aos contratos de construção. O objetivo é analisar se após as mudanças na forma de contabilização dos contratos de construção através do reconhecimento das receitas, com a adoção das IFRS pelas companhias abertas brasileiras do setor de Construção, houve alteração nos resultados das Receitas de Vendas, do Patrimônio Líquido e do Lucro/Prejuízo do período. Utilizou-se o método das estatísticas descritivas, com o intuito de avaliar o comportamento dos montantes das receitas, patrimônio líquido e resultados das empresas antes e depois da adoção das IFRS, no ano de 2009. O estudo demonstrou que, após a adoção das IFRS, ocorreu aumento nos valores do Patrimônio Líquido, das Receitas de Vendas e no Lucro/Prejuízo do período. Foi utilizado ainda o teste não paramétrico de Wilcoxon, após analisar o pressuposto da normalidade por meio dos testes de KolmogorovSmirnov e Shapiro-Wilk. Os resultados do teste de Wilcoxon demonstraram que os valores do patrimônio líquido, das receitas e do resultado das empresas do setor de Construção não sofreram variações significativas do ponto de vista estatístico.

Palavras-chave: Contratos de Construção. Adoção das IFRS. Demonstrações Contábeis.

ABSTRACT: This study aims to analyze the adoption of international accounting standards relating to construction contracts. The aim is to analyze whether after the changes in the accounting for construction contracts through the recognition of revenue, with the adoption of IFRS by Brazilian companies construction sector, there was change in the results of Sales Revenues, Net Equity and profit / Loss for the period. We used the method of descriptive statistics, in order to evaluate the behavior of the amounts of income, shareholders' equity and results of companies before and after the adoption of IFRS, in 2009. The study showed that after the adoption of IFRS caused an increase in value of shareholders' equity, Sales Revenue and Profit / Loss for the period. It was even used the nonparametric Wilcoxon test, after examining the normality assumption by the Kolmogorov-Smirnov and Shapiro-Wilk tests. The results of the Wilcoxon test showed that the values of equity, revenues and results of companies in the construction sector did not suffer significant variations from a statistical point of view

Keywords: Construction Contracts. Adoption of IFRS. Financial Statements. 


\section{INTRODUÇÃO}

O Brasil tem seguido a tendência mundial de adoção às normas internacionais de contabilidade, tendo em vista o padrão atual de convergência internacional, através da adoção das IFRS (International Financial Reporting Standard), emitidas pelo Comitê Internacional de Contabilidade (IASB-International Accounting Standards Board).

Neste contexto, com a expansão do mercado de capitais em todo o mundo e da crescente necessidade das empresas por obterem recursos disponíveis nesse mercado, isso tem levado as empresas brasileiras a buscarem recursos em bolsas de valores de outros países, os quais possuem normas contábeis diferentes das utilizadas no Brasil. Um dos grandes desafios da contabilidade, defendidos por Iudícibus et al. (2010, p. 591), relativos à evidenciação, tem sido a qualidade e a quantidade de informações que atendam às necessidades dos usuários das demonstrações contábeis, principalmente os externos.

Ainda destacam-se argumentos em defesa da convergência das normas internacionais de contabilidade, ou consequente adoção das IFRS, as quais dizem respeito à melhoria da qualidade das informações contábeis e, por conseguinte, da comunicação entre as companhias e os usuários de suas informações (MARTINS; PAULO, 2010, p. 31). Estes autores ainda defendem que a literatura indica que a adoção das IFRS influencia as demonstrações financeiras das organizações, no entanto, poucos pesquisadores utilizam evidências empíricas para descreverem efetivamente o reflexo dessa adoção sobre os resultados das companhias abertas brasileiras. Curcino et. al. (2014) ressaltam que:

\footnotetext{
““.... Com a criação de um novo padrão contábil brasileiro, por meio da convergência as Normas Internacionais de Contabilidade, surgiram algumas contas e conceitos novos que mudaram o tradicional plano de contas. Dentre as alterações ocorridas, destaca-se a obrigatoriedade da divulgação do lucro abrangente, evidenciado na Demonstração do Resultado Abrangente, que é um relatório previsto nas IFRS, com reflexo nos CPCs. Em relação à aderência de companhias abertas brasileiras, listadas no índice Bovespa, às Normas Internacionais de Contabilidade, no que tange à divulgação do resultado abrangente, evidenciou-se que somente 39 empresas divulgaram a DRA concomitantemente em 2010, $2011 \mathrm{e}$ 2012. Sendo assim, os testes realizados apontaram que não existem impactos desta forma de reconhecimento do lucro sobre os indicadores financeiros de rentabilidade ROE e EPS, visto que não existem diferenças significativas entre os indicadores calculados sob as duas formas de mensuração do lucro líquido e abrangente (CURCINO et. al. 2014).
}

Por essa razão, pretende-se adentrar no estudo das adoções das normas internacionais de contabilidade no que se refere aos contratos de construção, já que este setor é um importante instrumento de produção, desenvolvimento e crescimento econômico dos países. O Brasil, em decorrência do aumento dos investimentos e da maior disponibilidade de crédito no setor da Construção, também apresenta forte crescimento econômico e desenvolvimento nesta área de atuação.

O reconhecimento das receitas nos contratos de construção é bastante peculiar, tendo em vista que o assunto mais impactante referente à sua contabilização é o reconhecimento da receita e da despesa correspondente ao longo dos períodos de execução da obra. Os aspectos relacionados à identificação do contrato como um contrato de construção, como contrato de prestação de serviços ou contrato de venda de bens impactam diretamente na forma como as receitas devem ser reconhecidas. Diante disso, surge a problemática: será que a adoção das IFRS provocou, durante o período pesquisado, alteração nos valores do Patrimônio Líquido, das Receitas de Vendas e no Lucro/Prejuízo das empresas do setor da Construção?

R. Cont. Ufba, Salvador-Ba, v. 9, n. 3, p. 05 - 17, set-dez 2015 
Desta forma, o objetivo deste trabalho é analisar se, após as mudanças na forma de contabilização dos contratos de construção, através do reconhecimento das receitas, com a adoção das IFRS pelas companhias abertas brasileiras do setor de Construção, ocorreu alteração nos seus resultados. Considerando que tanto o CPC 17 - Contratos de Construção, quanto o ICPC 02, que trata de Contratos de Construção do Setor Imobiliário, são de aplicação obrigatória a partir de 2010.

O trabalho está estruturado da seguinte forma: a primeira seção trata da introdução; a seção seguinte discute a fundamentação teórica utilizada; a terceira apresenta os procedimentos metodológicos, a quarta parte traz a discussão e análise dos resultados e, por último, as considerações finais e, em seguida, as referências.

\section{REFERENCIAL TEÓRICO}

O CPC (Comitê de Pronunciamentos Contábeis) adotou integralmente o documento de convergência às Normas Internacionais de Contabilidade do IASB (International Accounting Standards Board), pois o CPC busca a primazia da essência sobre a forma, bandeira essa levantada praticamente ao extremo pelo IASB. (IUDÍCIBUS et. al., 2010, p. 31). No Brasil, verificam-se as alterações na Lei Societária e a publicação contínua dos Pronunciamentos técnicos do CPC (CURCINO et. al. 2014).

Niyama (2010, p. 37) afirma que "a convergência implica na aderência ou adoção de uma regra à outra, no caso brasileiro à internacional". O que permite a comparabilidade, compreensão e interpretações de informações geradas por entidades de diferentes países.

\subsection{Contratos de Construção}

O reconhecimento das receitas e da despesa correspondente, nos contratos de construção, ao longo dos períodos de execução da obra, é o assunto primordial referente à contabilização dos contratos de construção. Por isso, dar-se-á maior atenção a este tratamento contábil neste tópico do artigo.

Niyama et. al. (2011) ressaltam que é essencial, embora os critérios de reconhecimento de receitas e despesas sejam de adoção obrigatória por parte das empresas brasileiras, a flexibilidade proporcionada por tais critérios, assim como as particularidades dos contratos resultam na possibilidade de aplicação de práticas distintas.

A receita deve ser reconhecida como elemento da empresa quando é parte do produto da organização, quando pode ser medida, quando possui valor preditivo ou valor de feedback (HENDRIKSEN; BREDA, 1999).

O contrato de construção abrange, conforme trata o item 4 do CPC 17, a negociação para a elaboração de ativo único, tal como: uma ponte, um edifício, uma barragem, um oleoduto, uma estrada, um navio ou um túnel. Também pode ser definido pelo item 3 do CPC 17 como "um contrato especificamente negociado para a construção de ativo ou de combinação de ativos que sejam inter-relacionados ou interdependentes em função da sua concepção, tecnologia e função, ou do seu propósito ou uso final"'.

Ainda conforme o CPC 17, os contratos de construção incluem: a) contratos para a prestação de serviços que estejam diretamente relacionados com a construção do ativo; por exemplo, os relativos a serviços de arquitetos e de gestão de projetos; b) contratos para a destruição ou restauração de ativos e de recuperação ambiental após a demolição ou retirada de ativos.

Para Ernest \& Young (2010, p. 5) a norma CPC 17 (IAS 11) requer que as receitas e as despesas decorrentes dos contratos de construção sejam reconhecidas durante a execução

R. Cont. Ufba, Salvador-Ba, v. 9, n. 3, p. 05 - 17, set-dez 2015 
dos contratos, a fim de apresentar de forma consistente o resultado das atividades da entidade durante tal período. Desta maneira, a despesa é o reconhecimento, no resultado, de custos da construção que se contrapõem às receitas apropriadas.

Parte da literatura contábil entende que o momento da realização da receita é o momento em que ocorre uma venda, ou seja, a capacidade de realização da receita significa a capacidade de converter ativos não monetários e direitos em dinheiro. Este momento pode ser conhecido, também, como o ponto de transferência do bem. Nesse sentido, o momento do reconhecimento dos ganhos deve ser idêntico ao do reconhecimento de receitas.

Segundo Hendriksen e Breda (1999, p. 230-231), a realização da receita pode ocorrer de várias formas, dentre elas: a) O Registro de Receita durante a Produção: neste caso, os registros são prestados por período e sua prestação pode ser considerada essencial para a empresa. Um exemplo são os contratos de longo prazo, geralmente de acordo com o método da porcentagem completada como o que ocorre na Construção Civil; b) Registro de Receita na Conclusão da Produção: quando um produto é concluído, o custo de produção pode ser dirimido com um grau razoável de precisão. A consideração mais importante deve ser a capacidade de obter medidas confiáveis e verificáveis de receitas e custos adicionais; c) Registro de Receita no Momento da Venda: por muitos anos, o ato de entrega tem representado a regra geral para a divulgação de receita. As incertezas concernentes à mensuração são mínimas no momento da entrega, mas ainda não serão eliminadas. d) Registro de Receita Após a Venda: as situações nas quais o reconhecimento pode ser adiado para momento posterior a venda, incluem vendas com direito de devolução e vendas a prestação.

\subsubsection{A Mensuração e o Reconhecimento das Receitas nos Contratos de Construção}

De acordo com o item 12 - CPC 17, a receita do contrato de construção deve ser medida pelo valor justo da retribuição recebida ou a receber. Esse valor pode aumentar ou diminuir em função: das variações ou reivindicações do contrato; dos contratos de preço fixo elevarem o valor em consequência de cláusulas de aumento de custos; das penalidades provenientes de atrasos imputáveis ao contratado relativos à conclusão do contrato; ou do contrato de preço fixo estar relacionado à conclusão de cada unidade, desse modo a receita do contrato aumenta na proporção das unidades concluídas.

$\mathrm{O}$ reconhecimento da receita ocorre, conforme o item 22 - CPC 17, quando a conclusão do contrato de construção puder ser estimada com segurança. A receita e a despesa (transferência do custo para o resultado) associada ao contrato de construção devem ser reconhecidas tomando como base a proporção do trabalho executado até a data do balanço.

O reconhecimento da receita e da despesa referentes à fase de conclusão de um contrato é muitas vezes referido como o Método da Percentagem Completada, também conhecido como POC (Percentage of Completion). Neste método, a receita contratual deve ser proporcional aos custos contratuais incorridos em cada etapa de medição. Desta forma, proporciona informação útil sobre a extensão da atividade e o desempenho do contratado durante a execução do contrato.

Conforme o item 26 - CPC 17 (IAS 11), pelo método do POC, a receita do contrato é reconhecida na demonstração do resultado nos períodos contábeis em que o trabalho for executado. $\mathrm{O}$ mesmo ocorrendo com as despesas do trabalho. Porém, qualquer excedente dos custos totais esperados sobre as receitas totais do contrato deve ser reconhecido imediatamente como despesa (perda). E ainda, a entidade está geralmente em condições de

R. Cont. Ufba, Salvador-Ba, v. 9, n. 3, p. 05 - 17, set-dez 2015 
fazer estimativas confiáveis após assinar um contrato que estabeleça, de acordo com o item 29 - CPC 17: a) os direitos e deveres de cada uma das partes, no que diz respeito ao ativo a ser construído; b) a remuneração a ser paga; e c) a forma e os termos de liquidação.

O período de execução de um contrato pode ser determinado de várias maneiras. A entidade usa o método que mensura de forma mais confiável o trabalho executado. Dependendo da natureza do contrato, os métodos podem incluir, conforme o item 30 - CPC 17: a) a proporção dos custos incorridos até a data, em contraposição aos custos estimados totais do contrato; b) medição do trabalho executado; e c) execução de proporção física do trabalho contratado. Os pagamentos progressivos e os adiantamentos recebidos dos clientes não refletem, necessariamente, o trabalho executado, e por isso não devem servir de parâmetro para mensuração da receita.

\subsection{Contratos de Construção do Setor Imobiliário}

O setor da Construção Imobiliária é alvo de grandes investimentos e demanda, além de ser uma das bases do desenvolvimento econômico de um país. Este segmento influencia diretamente o bem-estar da sociedade, através da habitação, como também a possibilidade de emprego na Construção Civil, decorrente do seu constante crescimento, como o que ocorre na economia brasileira.

Ressalta-se que a expressão Unidade Imobiliária, conforme Iudícibus et al. (2010, p. 387), é utilizada para designar: 1) o terreno adquirido para venda, com ou sem construção; 2) cada lote oriundo de desmembramento de terreno; 3) cada terreno decorrente de loteamento; 4) cada unidade distinta resultante de incorporação imobiliária; 5) o prédio construído para venda como unidade isolada ou autônoma.

Por isso, a necessidade de um pronunciamento específico para este segmento, assim, tem-se a Interpretação Técnica ICPC 02, que é correlata às Normas Internacionais de Contabilidade - IFRIC 15. Esta interpretação abrange a contabilização das receitas e dos custos correspondentes das entidades que realizam a incorporação e/ou construção de imóveis, diretamente ou por meio de subempreiteiras.

Ernest \& Young (2010, p. 5) ressaltam que a IFRIC 15 é aplicável à contabilização das receitas e dos custos que se transformam e às despesas das entidades que realizam a construção e incorporação de imóveis. Além disso, a IFRIC 15 estabelece os requisitos necessários para determinar se os respectivos contratos devem ser reconhecidos de acordo com a IAS 11 (por se tratarem de contratos de construção ou de prestação de serviços), ou conforme a IAS 18 - Receitas (quando o que prevêem é a futura entrega de bens).

Conforme o ICPC 02 - Contratos de Construção do Setor Imobiliário, um contrato de construção de imóvel enquadra-se na definição de contratos de construção quando o comprador é capaz de especificar os principais elementos estruturais do projeto do imóvel antes de começar a construção e/ ou especificar mudanças estruturais significativas após o início da construção (quer o comprador utilize ou não essa possibilidade).

\subsubsection{Como Reconhecer as Receitas nos Contratos de Construção de um Imóvel}

A questão levantada neste tópico é saber como utilizar o reconhecimento de receita adequado a cada tipo de contrato, seja ele: um contrato de construção, um contrato de prestação de serviços ou um contrato de venda de bens.

Para determinar se o contrato de construção de um imóvel se enquadra no alcance da IAS 11 (CPC 17) ou IAS 18 (CPC 30) é preciso considerar os termos do contrato e todos os fatos e circunstâncias relacionados.

R. Cont. Ufba, Salvador-Ba, v. 9, n. 3, p. 05 - 17, set-dez 2015 
Essa determinação exige uma análise com relação a cada contrato, com foco na prevalência da essência econômica sobre a forma, fundamentada pelo CPC 17. Portanto, pode-se entender:

a) Um contrato de construção de imóvel é identificado como um contrato de construção quando o comprador é capaz de especificar os principais elementos estruturais do projeto do imóvel antes de começar a construção e/ou especificar mudanças estruturais significativas após o início da construção. Desta maneira, o seu reconhecimento será através do POC.

Um contrato é de prestação de serviços somente de acordo com a norma de Receitas e quando a empresa não for obrigada a comprar e fornecer materiais de construção. $\mathrm{O}$ reconhecimento da receita, neste caso, será através do critério do método de evolução da obra, ou seja, quando o desfecho de transação que envolva a prestação de serviços puder ser confiavelmente estimado. O reconhecimento da receita associada a essa transação deverá ser pelo método de proporção dos serviços prestados até a data do balanço, que também é conhecido pela sigla POC.

O contrato é de venda de bens quando a entidade for requisitada a prestar serviços em conjunto com o fornecimento de materiais de construção para cumprir sua obrigação contratual, a fim de entregar o imóvel ao comprador, como por exemplo, aqueles aplicáveis aos contratos de venda decorrentes da incorporação de unidades imobiliárias. Neste caso, o critério de reconhecimento da receita será com base no pronunciamento do CPC 30 (IAS 18). Este diz que a receita proveniente da venda de bens deve ser reconhecida quando forem satisfeitas todas as seguintes condições:

(i) a entidade tenha transferido para o comprador os riscos e benefícios mais significativos inerentes à propriedade dos bens;

(ii) a entidade não mantenha envolvimento continuado na gestão dos bens vendidos em grau normalmente associado à propriedade, nem efetivo controle de tais bens;

(iii) o valor da receita possa ser confiavelmente mensurado;

iv) for provável que os benefícios econômicos associados à transação fluirão para a entidade; $\mathrm{e}$

(v) as despesas incorridas ou a serem incorridas, referentes à transação, possam ser confiavelmente mensuradas.

Portanto, só será possível a adoção do CPC 30 (IAS 18) no caso do comprador, de acordo com o contrato, tiver reduzida possibilidade de influenciar no projeto do imóvel ou de solicitar pequenas modificações em relação ao projeto original. Por outro lado, quando uma entidade reconhecer a receita utilizando o POC, ela deve divulgar, conforme o ICPC 02 (IFRIC 15): “(i) os critérios utilizados nos contratos que atendem a todos os requerimentos de reconhecimento de receitas; (ii) o valor da receita proveniente desses contratos no período; e (iii) os métodos usados para determinar o percentual de evolução da obra".

No entanto, em relação aos contratos que estiverem em andamento na data do relatório, a entidade também deve divulgar: (a) o valor total dos custos incorridos e dos lucros reconhecidos (menos perdas reconhecidas) até aquela data; e (b) o valor dos adiantamentos recebidos. 


\section{PROCEDIMENTOS METODOLÓGICOS}

\subsection{Métodos e Técnicas}

Esta pesquisa é descritiva, em relação à sua classificação, pois busca identificar as possíveis mudanças que a adoção das normas internacionais de contabilidade pode causar no Patrimônio Líquido, nas Receitas e nos Lucros/Prejuízos das empresas do setor de Construção que estão listadas na BM\&FBOVESPA. Quanto à abordagem do problema, a pesquisa é de natureza quantitativa, pois se utiliza de instrumentos estatísticos para o tratamento e análise dos dados.

Para o alcance dos resultados, foram feitas consultas e coleta de dados no site da BM\&FBOVESPA. Além disso, foram consultados órgãos que visam centralizar e uniformizar os procedimentos, orientações e interpretações do CPC, já que este segue as normas estabelecidas pelo IASB. Pois, conforme o item 2 da Orientação OCPC 04, a estrutura da norma internacional, tem como axioma subordinar qualquer norma emitida pelo IASB ao objetivo da contabilidade, que é o de demonstrar uma visão justa e verdadeira (true and fair view) da situação patrimonial das empresas, ou seja, a primazia da essência sobre a forma.

\subsection{Coleta dos Dados}

O setor de Construção das empresas listadas na BM\&FBOVESPA contempla os segmentos da Construção Civil, Construção Pesada, Engenharia Consultiva, Intermediação Imobiliária, Materiais de Construção e Serviços Diversos. Porém, os dois últimos segmentos não foram analisados por não terem relação com o tema abordado - Contratos de Construção -, que é a linha da pesquisa. Desta forma, foram pesquisadas 31 (trinta e uma) empresas. Contudo, quatro empresas ficaram de fora: a Cimob Participações S.A. não entrou na análise, pois seus dados não foram disponibilizados; a Tecnosolo Engenharia S/A também, pois suas notas explicativas afirmaram que ela utiliza apenas as práticas adotadas no Brasil para a elaboração e apresentação das demonstrações contábeis. A Construtora Beter S.A. e a Mendes Júnior Engenharia S.A. disponibilizaram apenas as demonstrações individuais antes das adoções das IFRS em 2009. Desta maneira, restaram 27 (vinte e sete) empresas do Setor de Construção que adotaram as IFRS em 2009, para fins de comparação com 2010. A escolha do período se deu em função do ano da adoção das IFRS pelas companhias abertas brasileiras.

Para fins da pesquisa, foram analisadas as notas explicativas do ano de $2010 \mathrm{e}$ coletados os valores das Receitas de Vendas, Lucro/Prejuízo do período e Patrimônio Líquido consolidado antes e depois da adoção das IFRS referentes ao ano de 2009. Os dados foram retirados das Demonstrações dos Resultados e do Balanço Patrimonial das empresas investigadas. Essa consulta e coleta foram feitas do site da BM\&FBOVESPA.

Foram observadas as notas explicativas das empresas analisadas e, conforme foi analisado, o segmento da Construção Civil aplicou as práticas de acordo com as adotadas no Brasil e com as normas internacionais de relatório financeiro, sendo adotadas as IFRS para as demonstrações consolidadas. Quanto ao segmento da construção pesada, estas empresas, em sua maioria, adotaram as duas práticas para a elaboração e apresentação das demonstrações contábeis, sendo utilizadas as práticas adotadas no Brasil para demonstrações individuais e outras particularidades, especificadas nas notas explicativas, e adotadas as IFRS para as demonstrações consolidadas. 
No segmento de Engenharia Consultiva, apenas com duas empresas listadas, observou-se, conforme as notas explicativas, que uma delas, a Sondotécnica Engenharia Solos S.A., adotou as duas práticas, conforme a maioria das empresas analisadas e, a outra, a Tecnosolo Engenharia S/A, utilizou apenas as práticas adotadas no Brasil para a elaboração e apresentação das demonstrações contábeis. Para as empresas do segmento de Intermediação Imobiliária também foi possível observar que todas as empresas deste segmento adotaram as duas práticas para a elaboração e apresentação das demonstrações contábeis.

Percebeu-se, portanto, que a maioria das empresas adotou as duas práticas contábeis, as já adotadas anteriormente e as exigidas pelas normas internacionais de contabilidade.

\subsection{Tratamento dos Dados}

Quanto ao tratamento dos dados, inicialmente, calcularam-se as estatísticas descritivas das variáveis, isto com o intuito de avaliar o comportamento dos montantes das Receitas, Patrimônio Líquido e Resultados das empresas, antes e depois da adoção das IFRS que contemplam a IAS 11/CPC 17 - Contratos de Construção, e a IFRIC 15/ICPC 02, que trata de Contratos de Construção do Setor Imobiliário.

$\mathrm{Na}$ sequência, com o objetivo de avaliar se a adoção das novas práticas causou mudanças significativas nas variáveis em questão, utilizou-se o teste não paramétrico de Wilcoxon. Tal procedimento se justificou após analisar o pressuposto da normalidade por meio dos testes de Kolmogorov-Smirnov e Shapiro-Wilk.

Tabela 1 - Dados comparativos do ano de 2009, antes e depois da adoção das IFRS.

\begin{tabular}{|c|c|c|c|c|c|c|}
\hline \multirow{2}{*}{$\begin{array}{c}\text { Comparativo em } 2009 \\
\text { Empresas }\end{array}$} & \multicolumn{2}{|c|}{$\begin{array}{c}\text { Patrimônio Líquido } \\
\text { (mil reais) }\end{array}$} & \multicolumn{2}{|c|}{$\begin{array}{r}\begin{array}{r}\text { Receita de Vendas } \\
\text { (mil reais) }\end{array} \\
\end{array}$} & \multicolumn{2}{|c|}{$\begin{array}{c}\text { Lucro/Prejuízo } \\
\text { (mil reais) }\end{array}$} \\
\hline & $\begin{array}{l}\text { Antes das } \\
\text { IFRS }\end{array}$ & $\begin{array}{r}\text { Depois das } \\
\text { IFRS }\end{array}$ & \begin{tabular}{|c|} 
Antes das \\
IFRS
\end{tabular} & $\begin{array}{c}\text { Depois } \\
\text { das IFRS }\end{array}$ & $\begin{array}{l}\text { Antes das } \\
\text { IFRS }\end{array}$ & \begin{tabular}{|c|} 
Depois \\
das IFRS
\end{tabular} \\
\hline Azevedo e Travassos S.A. & 5.412 & 5.425 & 417.781 & 417.781 & 15.926 & 15.933 \\
\hline Brasil Brokers Part. S.A. & 414.505 & 388.903 & 249.341 & 281.851 & 44.927 & 45.321 \\
\hline Brookfield Inc. S.A. & 2.417 .256 & 2.417 .256 & 1.812 .012 & 1.812 .012 & 201.887 & 201.887 \\
\hline Brookfield SP Emp. Imob. & 233.164 & 233.164 & 457.879 & 457.879 & 14.452 & 14.452 \\
\hline Camargo Correa Des. Imob. & 675.369 & 675.369 & 514.073 & 514.073 & 58.007 & 58.007 \\
\hline Const. Adolpho Lindenberg & -27.575 & -27.575 & 9.784 & 9.784 & -893 & -893 \\
\hline Const. Lix da Cunha S.A. & 56.846 & 54.389 & 7.561 & 7.561 & 1.341 & 1.341 \\
\hline Construtora Sultepa S.A. & 236.615 & 256.242 & 145.531 & 124.168 & 14.706 & 13.321 \\
\hline CR2 Empreendimentos & 379.968 & 379.968 & 300.099 & 300.099 & 15.096 & 14.642 \\
\hline Cyrela Brazil Realty S.A. & 3.852 .804 & 3.852 .804 & 4.087 .825 & 4.087 .825 & 729.349 & 826.898 \\
\hline Direcional Engenharia S.A. & 656.413 & 656.413 & 377.613 & 377.613 & 79.095 & 79.095 \\
\hline$\overline{\text { Even Cons }}$ & 885.792 & 352 & 1.1 & 1.983 .819 & 124 & 135.638 \\
\hline EZ TEC Emp. e Part. S.A. & 912.673 & 924 & 50 & 505.978 & 16 & 163.191 \\
\hline GAFISA S.A. & 2.325 .634 & 2.325 .634 & 3.022 .346 & 3.022 .346 & 213.540 & 142.962 \\
\hline Helbor Emp. S.A. & 420.981 & 429.833 & 655.333 & 655.333 & 78.670 & 78.670 \\
\hline JHSF Participações S.A. & 932.808 & 916.441 & 496.410 & 496.410 & 149.171 & 155.938 \\
\hline João Fortes Engenharia S.A. & 237.955 & 245.907 & 290.283 & 290.283 & 65.844 & 60.305 \\
\hline LPS Brasil Cons. de Imóveis & 14.138 & 13.338 & 224.693 & 224.693 & 49.997 & 24.572 \\
\hline MRV Eng. E Part. S.A. & 2.392 .920 & 2.523 .274 & 1.647 .580 & 1.647 .580 & 347.422 & 374.066 \\
\hline PDG Realty S.A. Emp. e Part. & 2.940 .820 & 2.933 .624 & 1.983 .819 & 1.983 .819 & 338.132 & 338.132 \\
\hline Rodobens Neg. Imob. S.A. & 622.814 & 622.833 & 466.337 & 466.337 & 27.770 & 27.770 \\
\hline Rossi Residencial S.A. & 2.283 .413 & 2.252 .620 & 1.572 .285 & 1.572 .285 & 218.099 & 203.563 \\
\hline Sergen Serv. Ger. Eng. S.A. & 104.628 .726 & 106.305 .386 & 1.495 .292 & 1.674 .719 & -530.068 & -530.068 \\
\hline
\end{tabular}

R. Cont. Ufba, Salvador-Ba, v. 9, n. 3, p. 05 - 17, set-dez 2015 


\begin{tabular}{c|l|l|l|l|l|l}
\cline { 1 - 4 } Sondotecnica Eng. Solos S.A. & 61.571 & 61.601 & 77.461 & 77.461 & 10.750 & 7.408 \\
\hline Tecnisa S.A. & 880.475 & 983.111 & 710.708 & 737.197 & 110.536 & 110.536 \\
\hline Trisul S.A. & 462.348 & 463.024 & 560.184 & 560.184 & 51.516 & 51.389 \\
\hline Viver Inc. e Const. S.A. & 793.946 & 793.946 & 488.150 & 488.150 & 12.973 & 12.973 \\
\hline
\end{tabular}

Fonte: Elaboração própria, a partir de dados coletados do site BM\&FBOVESPA (2015).

R. Cont. Ufba, Salvador-Ba, v. 9, n. 3, p. 05 - 17, set-dez 2015 


\section{APRESENTAÇÃO E DISCUSSÃO DOS RESULTADOS}

Com base nos dados coletados, utilizou-se a técnica das estatísticas descritivas como ferramenta auxiliar a verificação do comportamento do Patrimônio Líquido, das Receitas de Vendas e do Lucro/Prejuízo, com a adoção das normas internacionais de contabilidade. A tabela 2 apresenta as estatísticas descritivas do estudo, a seguir:

Tabela 2 - Estatísticas Descritivas das Variáveis.

\begin{tabular}{l|l|l|l|l|l|l}
\cline { 2 - 7 } & \multicolumn{2}{c}{ Patrimônio Líquido } & \multicolumn{2}{c}{ Receita de Vendas } & \multicolumn{2}{c}{ Lucro/Prejuízo } \\
\cline { 2 - 7 } & \begin{tabular}{l} 
Antes das \\
\multicolumn{1}{l}{}
\end{tabular} & $\begin{array}{l}\text { Depois das } \\
\text { IFRS }\end{array}$ & $\begin{array}{l}\text { Antes das } \\
\text { IFRS }\end{array}$ & $\begin{array}{l}\text { Depois das } \\
\text { IFRS }\end{array}$ & $\begin{array}{l}\text { Antes das } \\
\text { IFRS }\end{array}$ & $\begin{array}{l}\text { Depois das } \\
\text { IFRS }\end{array}$ \\
\hline Máximo (mil reais) & 104.628 .726 & 106.305 .386 & 4.087 .825 & 4.087 .825 & 729.349 & 826.898 \\
\hline Mínimo (mil reais) & -27.575 & -27.575 & 7.561 & 9.784 & -530.068 & -530.068 \\
\hline Média (mil reais) & 4.803 .622 & 6.229 .799 & 879.428 & 1.125 .892 & 96.505 & 119.960 \\
\hline Desvio Padrão & 19976799,81 & 22954333,5 & 966383,354 & 1034558,4 & 199635,6 & 237112,1 \\
\hline
\end{tabular}

Fonte: Dados da Pesquisa.

Tendo em vista que o reconhecimento das receitas nos contratos de construção é o assunto mais impactante referente à sua contabilização ao longo dos períodos de execução da obra, os aspectos relacionados à identificação do contrato como um contrato de construção, de prestação de serviços ou de venda de bens, impactam diretamente na forma como as receitas devem ser reconhecidas. (CPC, 2015).

Com base nas análises das estatísticas descritivas, observa-se que o valor máximo do Patrimônio Líquido (em mil reais) depois da contabilização com a adoção das normas internacionais passou de 104.628.726 para 106.305.386. Por sua vez, o valor máximo da Receita de Vendas manteve-se constante e o valor máximo do Lucro/Prejuízo (em mil reais) também cresceu, passou de 729.349 para 826.898 .

Pode-se observar que após a adoção das IFRS houve o aumento da média do valor do Patrimônio Líquido (em mil reais) que passou de 4.803.622 para 6.229.799. Nas Receitas de Vendas, o aumento na média (em mil reais) subiu de 879.428 para 1.125.892. Por fim, no Lucro/Prejuízo também houve um aumento na média, que passou de 96.505 para 119.960 (em mil reais). Portanto, está demonstrado que após a adoção das IFRS houve aumento nos valores do Patrimônio Líquido, das Receitas de Vendas e no Lucro/Prejuízo do período.

A fim de verificar se a distribuição das variáveis provém de uma distribuição normal, foram aplicados os testes de Kolmogorov-Smirnov e Shapiro-Wilk, como mostra a Tabela 3 a seguir:

Tabela 3 - Normalidade da Distribuição

\begin{tabular}{c|l|l|l|l|r|r}
\hline \multicolumn{7}{c}{ Teste de Normalidade } \\
\hline & \multicolumn{3}{c}{ Kolmogorov-Smirnov ${ }^{\text {a }}$} & \multicolumn{3}{c}{ Shapiro-Wilk } \\
\cline { 2 - 8 } & Statistic & Df & Sig. & Statistic & Df & Sig. \\
\hline PL Antes & 0,493 & 21 & 0 & 0,264 & 21 & 0,000 \\
\hline PL Depois & 0,494 & 21 & 0 & 0,264 & 21 & 0,000 \\
\hline Receita Antes & 0,26 & 21 & 0,001 & 0,799 & 21 & 0,001 \\
\hline Receita Depois & 0,265 & 21 & 0 & 0,813 & 21 & 0,001 \\
\hline Lucro/Prejuízo Antes & 0,25 & 21 & 0,001 & 0,828 & 21 & 0,002 \\
\hline Lucro/Prejuízo Depois & 0,258 & 21 & 0,001 & 0,802 & 21 & 0,001 \\
\hline
\end{tabular}

Fonte: Dados da Pesquisa. ${ }^{\mathrm{a}}$ Lilliefors Significance Correction.

R. Cont. Ufba, Salvador-Ba, v. 9, n. 3, p. 05 - 17, set-dez 2015 
Verifica-se que não há normalidade em nenhuma das variáveis analisadas nos testes de Kolmogorov-Smirnov e Shapiro-Wilk, pois o nível de significância de todas é inferior a 0,05. Dessa forma, utilizou-se o teste de Wilcoxon para amostras emparelhadas como uma alternativa não paramétrica ao teste $t$ de stundet, conforme Tabela 4.

Tabela 4 - Estatística do Teste Não Paramétrico de Wilcoxon

\begin{tabular}{c|c|c|c}
\hline \multicolumn{5}{c}{ Teste de Wilcoxon } \\
\hline & $\begin{array}{c}\text { PL Depois } \\
\text { PL Antes }\end{array}$ & $\begin{array}{l}\text { Receita Depois } \\
\text { Receita Antes }\end{array}$ & $\begin{array}{l}\text { Lucro/Prejuízo Depois } \\
\text { Lucro/Prejuízo Antes }\end{array}$ \\
\hline $\mathrm{Z}$ & $-1,647$ & $-1,604$ &,- 357 \\
\hline Asymp. Sig. (2-tailed) &, 099 &, 109 &, 721 \\
\hline
\end{tabular}

Fonte: Dados da Pesquisa.

Os resultados do teste de Wilcoxon demonstram que, para todas as variáveis tem-se um $p$-value $>0,05$, o que faz com que a hipótese nula não seja rejeitada, ou seja, os valores do Patrimônio Líquido, das Receitas e do Resultado das empresas do setor de Construção não sofreram variações significativas, do ponto de vista estatístico, com a adoção das normas internacionais de contabilidade, conforme trata a IAS 11/CPC 17 - Contratos de Construção, e a IFRIC 15/ICPC 02, que trata de Contratos de Construção do Setor Imobiliário.

Através da análise pelo método da estatística descritiva, observa-se que houve aumento após a adoção das IFRS nos valores do Patrimônio Líquido, das Receitas de Vendas e no Lucro/Prejuízo do período. Porém, pelo teste de Wilcoxon, essas variações no Patrimônio Líquido, nas Receitas de Vendas e no Lucro/Prejuízo do período não foram significativas do ponto de vista estatístico.

\section{CONSIDERAÇÕES FINAIS}

Os aspectos relacionados à identificação do contrato como um contrato de construção, como contrato de prestação de serviços ou contrato de venda de bens impactam diretamente na forma como as receitas devem ser reconhecidas. Assim, o artigo analisou se, após a adoção das IFRS pelas companhias abertas brasileiras do setor de Construção, as mesmas obtiveram aumentos nas Receitas de Vendas, no Patrimônio Líquido e no Lucro/Prejuízo do período.

Tendo em vista o padrão atual de convergência, reconhecido como internacional, através da utilização das IFRS, o referencial teórico contemplou a discussão acerca dos contratos de construção, quanto à mensuração e ao reconhecimento das receitas. Também foi feito um estudo sobre esses contratos para o setor imobiliário, bem como as peculiaridades do reconhecimento de receitas neste setor.

Desta maneira, o presente trabalho pretende contribuir com a discussão do tema sobre adoção das IFRS pelas empresas do setor de Construção, tendo em vista que as normas e os procedimentos contábeis que tratam dos Contratos de Construção estão em processo de discussão e evolução através de seus órgãos normatizadores.

Foi utilizada na pesquisa a consulta às notas explicativas disponibilizadas pelas empresas analisadas no site da BM\&FBOVESPA, para análise e interpretação das mesmas, e para um melhor entendimento do setor. Através destes dados, pôde-se observar que as empresas, em sua maioria, adotaram tanto as práticas brasileiras para demonstrações individuais, quanto as IFRS para as demonstrações consolidadas.

R. Cont. Ufba, Salvador-Ba, v. 9, n. 3, p. 05 - 17, set-dez 2015 
Nos resultados da pesquisa, foram calculadas as estatísticas descritivas das variáveis, com o intuito de avaliar o comportamento dos montantes das Receitas, Patrimônio Líquido e Lucro/Prejuízo das empresas, antes e depois da adoção das IFRS. Ficou demonstrado que após a adoção das IFRS houve aumento nos valores do Patrimônio Líquido, das Receitas de Vendas e no Lucro/Prejuízo do período.

E com o objetivo de avaliar se a adoção das novas práticas causou mudanças significativas nas variáveis em questão, utilizou-se o teste não paramétrico de Wilcoxon. Tal procedimento se justificou após analisar o pressuposto da normalidade por meio dos testes de Kolmogorov-Smirnov e Shapiro-Wilk.

Os resultados do teste de Wilcoxon demonstraram que os valores do Patrimônio Líquido, das Receitas e do Resultado das empresas do setor de Construção não sofreram variações significativas, do ponto de vista estatístico. Vale dizer que esta análise baseia-se nas variáveis utilizadas no estudo, bem como nos resultados dos anos verificados na presente pesquisa.

As limitações da pesquisa se dão em função dos anos analisados; logo se sugere estudos com anos posteriores aos anos da presente pesquisa e com outras variáveis pertinentes ao tema abordado. Propõe-se a realização de pesquisas que envolvam outras companhias abertas listadas na BM\&FBovespa sobre a sua aderência às Normas Internacionais de Contabilidade.

\section{REFERÊNCIAS}

BM\&FBOVESPA. Demonstrações Contábeis Consolidadas. Disponível em: <http://www.bmfbovespa.com.br>. Acesso em: 26. Out. 2015.

COMitê DE PRONUnCIAMENTOS CONTÁBEIS. Pronunciamentos Técnicos CPC. Brasília. Disponível em: <http://www.cpc.org.br>. Acesso em: 26. Out. 2015.

CURCINO, G. M.; LEMES, S.; BOTINA, R. A. Efeito do resultado Abrangente nos Indicadores de desempenho das Companhias Abertas brasileiras. Revista Evidenciação Contábil \& Finanças, ISSN 2318-1001, João Pessoa, v. 2, n. 3, p. 24-40, set./dez. 2014.

FIPECAFI; Ernst \& Young. Manual de Normas Internacionais de Contabilidade: IFRS versus Normas Brasileiras. 1. ed. São Paulo: Atlas, 2009.

HENDRIKSEN, Eldon S.; BREDA, Michael F. Van. Teoria da Contabilidade. Tradução Antônio Zoratto Sanvicente. São Paulo: Atlas, 1999.

INTERNATIONAL ACCOUNTING STANDARDS BOARD (IASB). International Accounting Standards - IAS 28. Disponível em: <http://www.iasb.org>. Acesso em: 23. Out. 2015.

IUDÍCIBUS, Sérgio de. et al. Manual de Contabilidade Societária. 1. ed. São Paulo: Atlas, 2010.

MARTINS, Orleans Silva; PAULO, Edílson. Reflexo da Adoção das IFRS na Análise de Desempenho das Companhias de Capital Aberto no Brasil. RCO - Revista de Contabilidade e Organizações - FEA-RP/USP, São Paulo, n. 9, v. 4, p. 30-54, mai-ago 2010.

R. Cont. Ufba, Salvador-Ba, v. 9, n. 3, p. 05 - 17, set-dez 2015 
NIYAMA, Jorge Katsumi. Contabilidade Internacional. 2. ed. São Paulo: Atlas, 2010.

NIYAMA, Jorge Katsumi; CAVALCANTE, Paulo Roberto Nóbrega; REZENDE, Isabelle Carlos Campos. Normas Contábeis Brasileiras, Norte-americanas e Internacionais aplicáveis ao setor de Construção Civil: uma análise comparativa numa empresa do Estado da Paraíba. In: IV Congresso ANPCont, 2010. Anais... Natal: ANPCont, 2010. CDROM.

R. Cont. Ufba, Salvador-Ba, v. 9, n. 3, p. 05 - 17, set-dez 2015 